\title{
Depressive Symptoms among Industrial Workers in Vietnam and Correlated Factors: A Multi-Site Survey
}

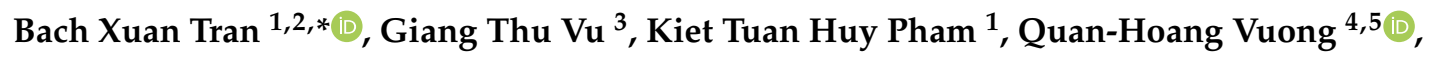 \\ Manh-Tung Ho ${ }^{4,5}{ }^{\circledR}$, Thu-Trang Vuong ${ }^{6}$, Hong-Kong T. Nguyen ${ }^{7}$, Cuong Tat Nguyen ${ }^{8}$, \\ Carl A. Latkin ${ }^{2}\left(D\right.$, Cyrus S.H. Ho ${ }^{9}$ and Roger C.M. Ho ${ }^{3,10,11(0)}$ \\ 1 Institute for Preventive Medicine and Public Health, Hanoi Medical University, Hanoi 100000, Vietnam; \\ phamhuytuankiet_vkt@fpt.vn \\ 2 Bloomberg School of Public Health, Johns Hopkins University, Baltimore, MD 21205, USA; \\ carl.latkin@jhu.edu \\ 3 Center of Excellence in Evidence-based Medicine, Nguyen Tat Thanh University, Ho Chi Minh City 70000, \\ Vietnam; giang.coentt@gmail.com (G.T.V.); pcmrhcm@nus.edu.sg (R.C.M.H.) \\ 4 Centre for Interdisciplinary Social Research, Phenikaa University, Yen Nghia, Ha Dong, Hanoi 100803, \\ Vietnam; hoang.vuongquan@phenikaa-uni.edu.vn (Q.-H.V.); tung.homanh@phenikaa-uni.edu.vn (M.-T.H.) \\ 5 Faculty of Economics and Finance, Phenikaa University, Yen Nghia, Ha Dong, Hanoi 100803, Vietnam \\ 6 Sciences Po Paris, Campus de Dijon, 21000 Dijon, France; thutrang.vuong@sciencespo.fr \\ 7 A.I. for Social Data Lab (AISDL), Vuong \& Associates Co., Hanoi 100000, Vietnam; \\ htn2107@caa.columbia.edu \\ 8 Institute for Global Health Innovations, Duy Tan University, Da Nang 550000, Vietnam; \\ cuong.ighi@gmail.com \\ 9 Department of Psychological Medicine, National University Hospital, Singapore, Singapore 119074, \\ Singapore; cyrushosh@gmail.com \\ 10 Department of Psychological Medicine, Yong Loo Lin School of Medicine, National University of Singapore, \\ Singapore 119228, Singapore \\ 11 Biomedical Global Institute of Healthcare Research \& Technology (BIGHEART), National University \\ of Singapore, Singapore 119228, Singapore \\ * Correspondence: bach.ipmph@gmail.com; Tel.: +84-982228662
}

Received: 25 March 2019; Accepted: 8 May 2019; Published: 11 May 2019

\begin{abstract}
Depressive disorders have been found to be a significant health issue among industrial workers, resulting from work-related factors and causing serious burdens for the workers as well as their employers. Literature on mental health problems of Vietnamese industrial workers has been limited, despite the rapid foreign investment-fueled industrialization process of the country. This study aimed to fill the gap in literature by examining the prevalence of depressive disorders and their potential associated factors among a cohort of Vietnamese industrial workers. A cross-sectional study was conducted in 3 industrial areas in Hanoi and Bac Ninh. A total of 289 workers agreed to participate in the study. Generalized linear mixed models were applied to identify associated factors with depression status of respondents. $38.6 \%$ of participants reported suffering depression. Factors found to be positively associated with the possibility of having depression and higher PHQ9 score were long working hours, suffering more health problems, and health hazards exposure at work. Meanwhile, being females, having more children, living with parents, engaging in smoking, and being local workers were found to correlate with lower likelihood of being depressed. The findings suggested the importance of regular health screening, work safety assurance, and social support outside of workplace on the mental health of the workers.
\end{abstract}

Keywords: depression; industrial workers; migrant workers; Vietnam 


\section{Introduction}

The World Health Organization (WHO) has classified common mental disorders, which include depressive and anxiety disorders, as "neurotic, stress-related, and somatoform disorders" and "mood disorders" [1]. These mental and behavioral disorders carry major weight in public health, as they are among the leading source of disease burden globally [2-4]. The burden of mental disorders on occupational health is particularly significant, since these disorders can lead work-related outcomes like absenteeism, sub-optimal performance at work, and high rate of turnover [5] which negatively affect both the workers and the employers. In developing countries, the previously neglected issue of psychological health of employees, especially of those working as industrial workers, has been brought into focus in recent years, amidst the rapid increase of the number of industrial factories established on foreign investment.

The relationship between the workplace and workers' mental health is a complex one [6]. While work itself can elevate an individual's well-being through its sense of job security, social contact, and organizational skills [7], a stress-inducing working environment could cause adverse mental health for the workers, which would in turn decrease their productivity and disrupt work [6,8,9]. A systematic review of research on work environment and depressive symptoms by Theorell, Hammarström [9] showed a substantial amount of empirical evidence for employees, both male and female, who lack control and face job strain and bullying to be at higher risks of depressive symptoms over time. Similarly, when looking at heavy industry workers who face high demand and have moderate control, Cantley, Cullen [8] found a higher risk of self-reported depression among these individuals. A number of studies have confirmed that industrial workers who reported high job strains and low social support to be suffering from depression and/or psychosocial distress, which includes social dysfunction, anxiety, and insomnia [10,11]. Meanwhile, a study on Latino manual laborers found that those who reported neck and shoulder pain were also more likely to present depressive symptoms [12].

Studies on factors associated with depression and anxiety in the general population have listed noise annoyance [13,14], air pollution [15-18], and elevated levels of environmental neurotoxicants $[19,20]$ as the outstanding elements. Translating to workplace environment, it is expected that these stressors would affect the mental health state of workers in some extent. In a different example, aircraft maintenance workers who are exposed to long-term low-level organophosphate esters tend to self-report depression [21]. Workplaces that are plagued by prolonged industrial relations conflict such as regular factory strikes may also increase the stress for workers, thereby driving up the likelihood of anxiety and depression [22]. For a large part, little is known about the accumulation of various factors in the industrial work environment that may be related to depression or other types of mentor disorder.

On the risk factors for depression, evidences from both developing and developed countries have shown depression to be associated with the female sex, especially those who suffer from severe life events, such as relationship crises, deaths, fertility or unwanted pregnancy, and lack social support in these circumstances [23-27]. In particular, women are about twice as likely as men to develop depression during their lifetime - an alarming gender gap that could be attributed to biological, psychological, and environmental factors [27]. Albert [26] suggested that "the differential risk may primarily stem from biological sex differences and depend less on race, culture, diet, education, and numerous other potentially confounding social and economic factors."

To the best of our knowledge, there has been a lack of study on the factors associated with depressive illness in industrial workers in Vietnam, especially in the recent context of increased foreign investment and industrialization [28]. In fact, the subject of mental health disorders in Vietnam has still been inadequately researched-to date we have found only one national-wide study conducted in 2001-2003 period that covered the topic, which reported the prevalence of depression among the Vietnamese population to be $2.8 \%$ [29], much lower than the figures reported for Japan $(18 \%)$, Iran (14.4\%), or China (13.2\%) [30,31]. To fill the gap, this study examined the exposure of Vietnamese workers at factories to factors correlated with depressive symptoms, situating the 
empirical findings within the bunk of international research on mental health of industrial workers in resource-scarce settings.

\section{Materials and Methods}

\subsection{Study Design}

A cross-sectional study was conducted from July to September 2018 in 3 industrial areas in Hanoi and Bac Ninh, two provinces with the most developed industrial zones in Northern Vietnam. In these areas, companies are manufacturing electronic components, vehicle accessories, automotive electronics, home electronics, telecommunications equipment, and control devices.

We approached respondents conveniently at their living areas by inviting them to attend a health communication meeting. We invited them to take the interview after the meeting and informed consent were given. A total of 289 workers agreed to participate in the study.

\subsection{Measure and Instruments}

Data were collected via 20-minute face-to-face interviews conducted by trained interviewers at a small private counseling room in order to protect their confidentiality. The purpose of the study, benefits, and drawbacks when participating in the study were introduced to participants, and then they were asked to join the study.

We conducted a pilot survey on 20 participants of different ages and genders, and only minor changes to the wording were made in order to meet participants' preferences and culture. Data concerning socio-economic characteristics, working conditions, depression level, health risk behavior, health-related quality of life, and social support situation of participants were collected, in particular:

\subsubsection{Socioeconomic Characteristics}

We asked participants to report their information about gender, age, education attainment, marital status, monthly income, and number of children in their family. We also collected the information regarding whether they were immigrant workers (i.e., migrated from regions of the countries rather than the current region of the factory in pursuit of work) or not.

\subsubsection{Working Conditions}

We asked each participants to report the following information: their years of working experience, number of working hours per day, whether they have been equipped with labor protection, and toxic factors which may cause occupational diseases that they were exposured to during working.

\subsubsection{Patient Health Questionnaire-9 (PHQ-9)}

To assess the levels of depression severity among participants, we used PHQ-9, a validated depression screening tool based on the Diagnostic and Statistical Manual of Mental Disorders (DSM-IV) criteria, including nine items. Each question would be pointed from 0 to 3, and the total score would be ranged from 0 to 27 . Depression severity was characterized as none (0-4), mild (5-9), moderate (10-14), moderately severe (15-19), and severe ( $\geq 20)$. A PHQ-9 score $\geq 10$ was seen as the cut off point for major depression with a sensitivity of $88 \%$ and a specificity of $88 \%$ [32].

\subsubsection{Health Risk Behavior}

Substance abuse behaviors were also investigated as potential covariates. We asked participants about drinking practices, which were measured using the Alcohol Use Disorders Identification Test-Consumption-AUDIT-C included three questions and the total score that participants received was from 0 to 12. Hazardous drinking was defined if the total score is higher than 4 for males and higher than 3 for females. Smoking status was classified into three main groups: current smokers, former 
smokers, and never-smokers. Current tobacco status were identified if participants smoked in the last 30 days and smoked 100 cigarettes or more in their lifetime. Those who had smoked 100 cigarettes or more in their lifetime but had not smoked in the last 30 days were classified as former smokers.

\subsubsection{Social Support}

Attitude of participants towards social support were reported including neighbourhood cohesion [33] (positive social support), neighbourhood disorder [34], and social disorder [34] (negative social support) around the living area. Each positive answer in terms of social support counted as 1 point. Social support score ranged from 0 to 8 points.

\subsection{Statistical Analysis}

Data were analyzed by STATA version 12 (Stata Corp. LP, College Station, TX, USA). We used Chi-square test to find the differences of categorical variables between depression and non-depression group. Meanwhile, Mann-Whitney test were employed on continuous variables Generalized linear mixed models (GLMM) were applied to identify associated factors with depression status of respondent. We used GLMM to account for the potential correlation of outcomes between participants from the same factory. We also estimated robust standard errors, adjusting for the clustering within factories. The study considered any variable with a $p$-value less than 0.05 as statistically significant.

\subsection{Ethics approval}

This study protocol was approved by the Institutional Review Board of Youth Research Institute, Hanoi, Vietnam (01a QĐ/VNCTN).

\section{Results}

Table 1 shows the prevalence of depression among our respondents to be $38.6 \%$. Regarding socio-economic profile, $83.3 \%$ of participants were female, $51.1 \%$ were immigrants, $91.3 \%$ had high school education or above, and $95.9 \%$ lived with spouse or partner. A high proportion of participants had 2 children $(64.1 \%)$. The mean age of participated worker was 31.9 years old and their monthly income was 273.6 USD per month. The mean PHQ9 score in non-depression group was 1.5 and this score in depression group was 9.1. There was statistically significant difference in terms of mean PHQ9 score between those reported not having depression and those reported having.

Table 1. Socio-economic characteristic of respondents.

\begin{tabular}{|c|c|c|c|c|c|c|c|}
\hline \multirow{3}{*}{ Characteristic } & \multicolumn{6}{|c|}{ Depression } & \multirow{3}{*}{$p$-Value } \\
\hline & \multicolumn{2}{|c|}{ No } & \multicolumn{2}{|c|}{ Yes } & \multicolumn{2}{|c|}{ Total } & \\
\hline & $n$ & $\%$ & $n$ & $\%$ & $n$ & $\%$ & \\
\hline Total & 177 & 61.3 & 112 & 38.6 & 289 & 100 & \\
\hline \multicolumn{8}{|l|}{ Gender } \\
\hline Male & 22 & 12.6 & 26 & 23.2 & 48 & 16.7 & 0.02 \\
\hline Female & 153 & 87.4 & 86 & 76.8 & 239 & 83.3 & \\
\hline \multicolumn{8}{|l|}{ Immigration status } \\
\hline Local people & 95 & 54.9 & 42 & 39.3 & 137 & 48.9 & 0.01 \\
\hline Immigrants & 78 & 45.1 & 65 & 60.8 & 143 & 51.1 & \\
\hline \multicolumn{8}{|l|}{ Education } \\
\hline Under high school & 20 & 11.4 & 5 & 4.5 & 25 & 8.7 & 0.09 \\
\hline High school & 101 & 57.7 & 75 & 67.0 & 176 & 61.3 & \\
\hline Above high school & 54 & 30.9 & 32 & 28.6 & 86 & 30.0 & \\
\hline
\end{tabular}


Table 1. Cont.

\begin{tabular}{|c|c|c|c|c|c|c|c|}
\hline \multirow{3}{*}{ Characteristic } & \multicolumn{6}{|c|}{ Depression } & \multirow{3}{*}{$p$-Value } \\
\hline & \multicolumn{2}{|c|}{ No } & \multicolumn{2}{|c|}{ Yes } & \multicolumn{2}{|c|}{ Total } & \\
\hline & $n$ & $\%$ & $n$ & $\%$ & $n$ & $\%$ & \\
\hline \multicolumn{8}{|l|}{ Marital status } \\
\hline Single & 7 & 4.0 & 5 & 4.5 & 12 & 4.2 & 0.83 \\
\hline Have spouse/partner & 170 & 96.1 & 107 & 95.5 & 277 & 95.9 & \\
\hline \multicolumn{8}{|l|}{ Number of children } \\
\hline 0 & 1 & 0.6 & 11 & 10.3 & 12 & 4.4 & $<0.01$ \\
\hline 1 & 23 & 13.6 & 21 & 19.6 & 44 & 15.9 & \\
\hline 2 & 112 & 66.3 & 65 & 60.8 & 177 & 64.1 & \\
\hline$>2$ & 33 & 19.5 & 10 & 9.4 & 43 & 15.6 & \\
\hline \multicolumn{8}{|l|}{ Currently living with } \\
\hline Parents & 83 & 47.4 & 52 & 46.4 & 135 & 47.04 & 0.87 \\
\hline Spouse & 142 & 81.1 & 91 & 81.3 & 233 & 81.18 & 0.98 \\
\hline Children & 108 & 61.7 & 67 & 59.8 & 175 & 60.98 & 0.75 \\
\hline Brothers/sisters & 14 & 8.0 & 7 & 6.3 & 21 & 7.32 & 0.58 \\
\hline Other & 1 & 0.74 & 10 & 7.0 & 11 & 3.96 & $<0.01$ \\
\hline \multicolumn{8}{|l|}{ Annual income quintile } \\
\hline 1 & 62 & 36.9 & 34 & 30.9 & 96 & 34.5 & 0.26 \\
\hline 2 & 48 & 28.6 & 42 & 38.2 & 90 & 32.4 & \\
\hline 4 & 24 & 14.3 & 18 & 16.4 & 42 & 15.1 & \\
\hline \multirow[t]{2}{*}{5} & 34 & 20.2 & 16 & 14.6 & 50 & 18.0 & \\
\hline & Mean & SD & Mean & SD & Mean & SD & \\
\hline Age & 32.5 & 4.9 & 31.0 & 3.6 & 31.9 & 4.5 & 0.03 \\
\hline PHQ9 score & 1.5 & 1.4 & 9.1 & 4.1 & 4.5 & 4.6 & $<0.01$ \\
\hline
\end{tabular}

Table 2 demonstrates the working conditions of the participants. The average working hours per day of the participants was 8 , the average years of experience was 10 . There were statistically significant differences in daily working hours and number of health hazards exposure at work between depressed and non-depressed participants. Workers who had depression were more exposed to toxic gas and accident-prone hazards at workplace $(p$-value $<0.01)$. In contrast, those who were not depressed had more exposure health hazards relating to high temperature ( $p$-value $=0.01$ ) and toxic chemical $(p$-value $=0.05)$.

Table 2. Working conditions of respondents.

\begin{tabular}{|c|c|c|c|c|c|c|c|}
\hline \multirow{3}{*}{ Characteristic } & \multicolumn{4}{|c|}{ Depression } & & & \multirow{3}{*}{$p$-Value } \\
\hline & \multicolumn{2}{|c|}{ No } & \multicolumn{2}{|c|}{ Yes } & \multicolumn{2}{|c|}{ Total } & \\
\hline & $n$ & $\%$ & $n$ & $\%$ & $n$ & $\%$ & \\
\hline \multicolumn{8}{|l|}{ Health hazards exposure at work $(n=278)$} \\
\hline Noise & 122 & 71.8 & 92 & 84.4 & 214 & 76.7 & 0.02 \\
\hline Dust & 80 & 47.1 & 60 & 55.1 & 140 & 50.2 & 0.19 \\
\hline Poor lightning & 11 & 6.5 & 14 & 12.8 & 25 & 9.0 & 0.07 \\
\hline High humidity & 13 & 7.7 & 13 & 11.9 & 26 & 9.3 & 0.23 \\
\hline Toxic chemicals & 53 & 31.2 & 47 & 43.1 & 100 & 35.8 & 0.04 \\
\hline \multirow[t]{2}{*}{ Accident prone working environment } & 15 & 8.8 & 27 & 24.8 & 42 & 15.1 & $<0.01$ \\
\hline & Mean & SD & Mean & $\mathrm{SD}$ & Mean & $\mathrm{SD}$ & \\
\hline
\end{tabular}


Table 3 indicates that $86.2 \%$ of the participants had never smoked. Percentage of people engaged in smoking and hazardous drinking were $7.3 \%$ and $13.7 \%$, respectively. Those who had depression had more health problems than those who did not (mean number of health problems were 2.5 and 1.5 respectively, $p$-value $<0.01)$.

Table 3. Health status and behavior of respondents.

\begin{tabular}{|c|c|c|c|c|c|c|c|}
\hline \multirow{3}{*}{ Characteristic } & \multicolumn{4}{|c|}{ Depression } & & & \multirow{3}{*}{$p$-Value } \\
\hline & \multicolumn{2}{|c|}{ No } & \multicolumn{2}{|c|}{ Yes } & \multicolumn{2}{|c|}{ Total } & \\
\hline & $n$ & $\%$ & $n$ & $\%$ & $n$ & $\%$ & \\
\hline \multicolumn{8}{|l|}{ Smoking status $(n=261)$} \\
\hline Never smoke & 133 & 86.4 & 92 & 86.0 & 225 & 86.2 & 1.00 \\
\hline Former smokers & 10 & 6.5 & 7 & 6.5 & 17 & 6.5 & \\
\hline Current smokers & 11 & 7.1 & 8 & 7.5 & 19 & 7.3 & \\
\hline Hazardous drinking $(n=277)$ & 19 & 11.2 & 19 & 17.4 & 38 & 13.7 & 0.14 \\
\hline \multicolumn{8}{|c|}{ Number of health problems $(n=280)$} \\
\hline 0 & 39 & 28.5 & 22 & 15.4 & 61 & 21.8 & 0.05 \\
\hline 1 & 36 & 26.3 & 44 & 30.8 & 80 & 28.6 & \\
\hline 2 & 26 & 19.0 & 39 & 27.3 & 65 & 23.2 & \\
\hline \multirow[t]{2}{*}{$>2$} & 36 & 26.3 & 38 & 26.6 & 74 & 26.4 & \\
\hline & Mean & $\mathrm{SD}$ & Mean & SD & Mean & SD & \\
\hline Number of health problems & 1.5 & 1.3 & 2.5 & 1.9 & 1.9 & 1.6 & $<0.01$ \\
\hline
\end{tabular}

Table 4 illustrates that people that had depression assumed that people in their living area were less willing to help each other/neighbors, less likely to be trusted and to share similar values, their living area had a tremendous amount of trash, and more social vices and fighting than was reported by people who did not have depression.

Table 4. Social support and community cohesion.

\begin{tabular}{|c|c|c|c|c|c|c|c|}
\hline \multirow{3}{*}{ Characteristic } & \multicolumn{4}{|c|}{ Depression } & & & \multirow{3}{*}{$p$-Value } \\
\hline & \multicolumn{2}{|c|}{ No } & \multicolumn{2}{|c|}{ Yes } & \multicolumn{2}{|c|}{ Total } & \\
\hline & $n$ & $\%$ & $n$ & $\%$ & $n$ & $\%$ & \\
\hline People around living place are willing to help neighbors & 93 & 57.8 & 54 & 50.0 & 147 & 54.7 & 0.21 \\
\hline People live in harmony & 97 & 60.3 & 52 & 48.2 & 149 & 55.4 & 0.05 \\
\hline This area has a tremendous amount of trash & 22 & 13.7 & 25 & 23.2 & 47 & 17.5 & 0.05 \\
\hline This area has society's vices & 11 & 6.8 & 15 & 13.9 & 26 & 9.7 & 0.06 \\
\hline \multirow[t]{2}{*}{ This area has many fights and quarrels } & 3 & 1.9 & 5 & 4.6 & 8 & 3.0 & 0.19 \\
\hline & Mean & SD & Mean & SD & Mean & $\mathrm{SD}$ & \\
\hline Social support (score) & 4.7 & 2.2 & 4.4 & 2.0 & 4.6 & 2.1 & 0.18 \\
\hline
\end{tabular}

Table 5 presents the factors associated with mental health status of participants. Those who were older, had more children, and were current smokers have statistically significant lower PHQ9 score as well as lower likelihood of having depression; while those having higher years of working and suffering more health problems were statistically more likely to have higher PHQ9 score and likelihood of being diagnosed with depression. Those who were former smokers and had higher social support score have statistically significant lower PHQ9 score, while having high school education and lower as well as longer daily working hours were found to have statistically significant correlation with higher PHQ9 score. Local workers were less likely to be depressed compared to their immigrated counterparts $(\mathrm{OR}=0.51, \mathrm{CI}=0.24-0.85)$. Females and those with hazardous drinking habits had statistically less chance of having depression. In addition, though not statistically significant, the results showed that 
those living with parents or children had lower likelihood of having higher PHQ9 score and suffering depression, while those living with spouse reported an opposite trend.

Table 5. Regression results of factors associated with depression among industrial workers.

\begin{tabular}{|c|c|c|c|c|}
\hline \multirow{2}{*}{ Characteristics } & \multicolumn{2}{|c|}{ PHQ9 Score } & \multicolumn{2}{|c|}{ Depression } \\
\hline & Coef. & $95 \% \mathrm{CI}$ & OR & $95 \% \mathrm{CI}$ \\
\hline \multicolumn{5}{|l|}{ Gender (Male-ref) } \\
\hline Female & -1.93 & $(-4.58-0.72)$ & $0.24^{* * *}$ & $(0.14-0.40)$ \\
\hline \multicolumn{5}{|l|}{ Education (Under Highschool-ref) } \\
\hline Highschool & $2.05 *$ & $(-0.19-4.29)$ & 2.51 & $(0.49-12.85)$ \\
\hline Above high school & 1.82 & $(-0.56-4.19)$ & $2.52^{* * *}$ & $(1.72-3.69)$ \\
\hline \multicolumn{5}{|l|}{ Marital status (Single-ref) } \\
\hline Living with spouse/partner & -0.39 & $(-3.44-2.65)$ & 1.34 & $(0.13-13.71)$ \\
\hline Number of children & $-1.10 * *$ & $(-1.94--0.26)$ & $0.47^{* * *}$ & $(0.27-0.82)$ \\
\hline Local people (Yes vs No) & -0.33 & $(-1.49-0.82)$ & $0.63^{* * *}$ & $(0.45-0.87)$ \\
\hline \multicolumn{5}{|l|}{ Currently living with } \\
\hline Parents (Yes vs No) & -0.75 & $(-2.00-0.51)$ & 0.82 & $(0.42-1.63)$ \\
\hline Spouse (Yes vs No) & 0.41 & $(-1.49-2.31)$ & 1.25 & $(0.47-3.33)$ \\
\hline Children (Yes vs No) & -0.13 & $(-1.43-1.17)$ & 0.93 & $(0.63-1.37)$ \\
\hline Age & $-0.16^{* *}$ & $(-0.31--0.01)$ & $0.92 *$ & $(0.85-1.00)$ \\
\hline Years of working & $0.17 *$ & $(-0.01-0.34)$ & $1.13^{* * *}$ & $(1.06-1.21)$ \\
\hline Working hours per day & $0.70 * *$ & $(0.07-1.33)$ & 1.36 & $(0.75-2.49)$ \\
\hline \multicolumn{5}{|l|}{ Smoking status (Never smoke - ref) } \\
\hline Former smokers & $-2.02 *$ & $(-4.43-0.39)$ & 0.64 & $(0.28-1.44)$ \\
\hline Current smokers & $-2.50 *$ & $(-5.38-0.38)$ & $0.45^{* * *}$ & $(0.35-0.57)$ \\
\hline \multicolumn{5}{|l|}{ Hazardous drinking (No-ref) } \\
\hline Yes & 0.48 & $(-2.27-3.24)$ & $0.50 * *$ & $(0.26-0.95)$ \\
\hline Social support (score) & $-0.27 * *$ & $(-0.54-0.00)$ & 0.92 & $(0.83-1.02)$ \\
\hline Number of health hazards exposure at work & 0.05 & $(-0.37-0.46)$ & 1.00 & $(0.97-1.04)$ \\
\hline Number of health problems & $0.53^{* * *}$ & $(0.15-0.92)$ & $1.37^{* * *}$ & $(1.24-1.52)$ \\
\hline
\end{tabular}

\section{Discussion}

Our study found a high prevalence of depression among a cohort of Vietnamese industrial workers. Multiple concurrent health problems and exposure to hazards at work has been found to positively correlated with the likelihood of suffering depression, while gender (female) and familial supports are negatively associated factors. These findings support the implementation of regular health check-up and psychological counselings, as well as having family involvements in controlling depression and improving the well-being of workers.

The prevalence of depression in our respondents was comparable to that reported by a number of studies on mental health of migrant workers in Australia-32.6\% [35], China-34.4\% [36], Peru-38.0\% [37], and Spain-39.5\% [38], while being almost 2.6 times higher than the figure of combined prevalence of 10 most common mental disorders in Vietnam (14.9\%), found in a national survey in 2002-2003 [29]. Previous studies on Chinese industrial workers suggested that industrial workers, especially those who had emigrated to pursue work at the factories, generally had a lower level of education, worked repetitive labor-intensive jobs, were not sufficiently covered by health insurance, and were with limited family and friends support $[39,40]$, which made them a vulnerable population with elevated risks of depression compared to other groups.

Investigating further into potential associated factors of depression among industrial workers, we found positive correlates that were also reported elsewhere: working long hours [41,42] and having more health problems [43]. On the other hand, being female was found to be negatively correlated with the likelihood of having depression, which may be considered contradictory with some research that has found women at workplace to have higher rates of depression than their male counterparts [44]. 
However, several studies on industrial workers indeed reported a higher proportion of male workers suffering depression than that of female workers [45] or no significant difference in gender regarding prevalence of depression [40]. Such findings may be explained by the fact that men may be more willing to take or more likely to be assigned more dangerous jobs or heavier workload, leading to longer working hours and increased work hazard exposures [45], raising their proneness to depression. With regard to our study, the sampling technique adopted may also be a reason for lower possibility of having depression in women.

In addition, our sample showed that having more children and having higher social support score were associated with lower possibility of having depression and with lower PHQ9 score. This result is somewhat in line with existing literature that cited lack of family support, for example absence of connection with family in terms of phone calls or visiting [40], as a risk factor for depression, especially in those moved away from hometown [46]. Thus, the role and current status of social support for industrial workers, in particular those migrated from other areas, should receive more attention from company managers, community, and policy-makers.

Albeit having a small number of participants reported as ever being smokers, our study also found that engaging in smoking, either currently or in the past, as well as hazardous drinking, was associated with lower likelihood of depression and with lower PHQ9 score. The reason for such a finding may be the fact that substance use, for instance, smoking, can be utilized as a coping mechanism for stress and depression [47], and thus smoking can arguably reduce the perceived depression symptoms among smokers [48]. Nevertheless, the impact of substance use on psychological distress, whether reducing or increasing, has still been debatable. Smoking and drinking as a potential coping mechanism for depression and work-related stress should be considered as a possibly significant health risk behavior among industrial workers, which would later result in more health issues that cause more stress and lead to depression.

Several implications can be drawn from our findings. First, regular health screening with a stronger emphasis on mental health and depression diagnosis should be conducted in all industrial factories. In addition to ensuring that the work safety requirements are being adhered to at all times to minimize work-related hazard exposures, support in a more informal and psychologically and socially-oriented form should be made available to those industrial workers. Incentives for workers to build their home in the area of the workplace, encouragement for periodical or regular visiting or connecting with their families in their hometown may be some of the suggestions for lowering the depression prevalence among industrial workers. Furthermore, regular education campaigns on healthy and health risk behaviors should be conducted to enhance the knowledge of those workers on health so that they can better manage their mental and physical condition.

The current study also has some limitations. First, the sampling method adopted may hinder the generalizability of our results. Future research should consider a larger and more diverse population to confirm the consistency of the empirical findings here. Nonetheless, the use of a structured questionnaire in this study allows for replication of research and provides a point of reference which may benefit future studies. Second, our findings may be subject to recall bias due to the self-reported nature of our survey. There were also missing responses, due to participants declining to give information when asked, reported for some questions, which may affect the interpretation of results and power of the study. However, such an effect is expected to be non-significant, since the missing rate was under $10 \%$ for all of these questions. Additionally, as a cross-sectional research, the study has not accounted for the progress of depressive symptoms and illness over time in these industrial workers.

\section{Conclusions}

Our study discovered a relatively high prevalence of depression among industrial workers. In addition, we investigated the correlation of gender, working conditions, social support, and health risk behaviors with the depression status of these workers. The findings suggested the importance of 
regular health screening, work safety and social support outside of workplace on the mental health of the workers.

Author Contributions: Conceptualization, B.X.T.; Data curation, G.T.V. and K.T.H.P.; Formal analysis, Q.-H.V., M.-T.H., T.-T.V., C.A.L. and C.S.H.; Methodology, B.X.T., K.T.H.P., H.-K.T.N., C.T.N., C.A.L. and R.C.M.H.; Project administration, B.X.T. and R.C.M.H.; Supervision, G.T.V.; Validation, H.-K.T.N. and R.C.M.H.; Writing-original draft, B.X.T., G.T.V., K.T.H.P., Q.-H.V., M.-T.H., T.-T.V., C.T.N., C.A.L., C.S.H. and R.C.M.H.; Writing-review \& editing, B.X.T., G.T.V., K.T.H.P., Q.-H.V., M.-T.H., T.-T.V., H.-K.T.N., C.T.N., C.A.L., C.S.H. and R.C.M.H.

Funding: This research received no external funding.

Conflicts of Interest: The authors declare no conflict of interest.

\section{References}

1. WHO. The ICD-10 Classification of Mental and Behavioural Disorders. The World Health Organization's International Classification of Diseases and Related Health Problems (ICD). 1992. Available online: https://www.who.int/classifications/icd/en/bluebook.pdf (accessed on 4 March 2019).

2. Mathers, C.D.; Loncar, D. Projections of global mortality and burden of disease from 2002 to 2030. PLoS Med. 2006, 3, e442. [CrossRef]

3. Murray, C.J. Disability-adjusted life years (DALYs) for 291 diseases and injuries in 21 regions, 1990-2010: A systematic analysis for the Global Burden of Disease Study 2010. Lancet 2013, 380, 2197-2223. [CrossRef]

4. Chisholm, D.; Sanderson, K.; Ayuso-Mateos, J.L.; Saxena, S. Reducing the global burden of depression: Population-level analysis of intervention cost-effectiveness in 14 world regions. Br. J. Psychiatry 2004, 184, 393-403.

5. Niedhammer, I.; Malard, L.; Chastang, J.F. Occupational factors and subsequent major depressive and generalized anxiety disorders in the prospective French national SIP study. BMC Public Health 2015, 15, 200. [CrossRef]

6. Rao, S.; Ramesh, N. Depression, anxiety and stress levels in industrial workers: A pilot study in Bangalore, India. Ind. Psychiatry J. 2015, 24, 23-28. [CrossRef] [PubMed]

7. Harnois, G.; Gabriel, P. Mental Health: Issues, Impact and Practices; World Health Organisation: Geneva, Switzerland, 2000; p. 5.

8. DeSanto Iennaco, J.; Cullen, M.R.; Cantley, L.; Slade, M.D.; Fiellin, M.; Kasl, S.V. Effects of externally rated job demand and control on depression diagnosis claims in an industrial cohort. Am. J. Epidemiol. 2009, 171, 303-311. [PubMed]

9. Theorell, T.; Hammarström, A.; Aronsson, G.; Bendz, L.T.; Grape, T.; Hogstedt, C. A systematic review including meta-analysis of work environment and depressive symptoms. BMC Public Health. 2015, 15, 738. [CrossRef]

10. Cha, B.S.; Koh, S.B.; Wang, S.J.; Chang, S.J. Effect of economic depression on psychosocial distress of industrial workers. Korean J. Occup. Environ. Med. 1998, 10, 484-492.

11. Rasoulzadeh, Y.; Bazazan, A.; Safaiyan, A.; Dianat, I. Fatigue and psychological distress: A case study among shift workers of an Iranian petrochemical plant, during 2013, in Bushehr. Iran. Red Crescent Med. J. 2015, 17, e28021. [CrossRef] [PubMed]

12. Tribble, A.G.; Summers, P.; Chen, H.; Quandt, S.A.; Arcury, T.A. Musculoskeletal pain, depression, and stress among Latino manual laborers in North. Carolina. Arch. Environ. Occup. Health 2016, 71, 309-316. [CrossRef] [PubMed]

13. Beutel, M.E.; Jünger, C.; Klein, E.M.; Wild, P.; Lackner, K.; Blettner, M.; Binder, H.; Michal, M.; Wiltink, J.; Münzel, T.; et al. Noise annoyance is associated with depression and anxiety in the general population-the contribution of aircraft noise. PLoS ONE 2016, 11, e0155357. [CrossRef]

14. Paiva, K.M.; Cardoso, M.R.A.; Zannin, P.H.T. Exposure to road traffic noise: Annoyance, perception and associated factors among Brazil's adult population. Sci. Total Environ. 2019, 650, 978-986. [CrossRef]

15. Zijlema, W.L.; Wolfb, K.; Emeny, R.; Ladwigbc, K.H.; Peters, A.; Kongsgårdd, H.; Hveeme, K.; Kvaløye, K.; Yli-Tuom, T.; Partoneng, T.; et al. The association of air pollution and depressed mood in 70,928 individuals from four European cohorts. Int. J. Hyg. Environ. Health 2016, 219, 212-219. [CrossRef]

16. Kawada, T. Air pollution and depressed mood: Consistency of association. Int. J. Hyg. Environ. Health 2016, 219, 477. [CrossRef] [PubMed] 
17. Vert, C.; Sánchez-Benavides, G.; Martínez, D.; Gotsens, X.; Gramunt, N.; Cirach, M.; LuisMolinuevo, J.; Sunyer, J.; Nieuwenhuijsen, M.J.; Crous-Bou, M.; et al. Effect of long-term exposure to air pollution on anxiety and depression in adults: A cross-sectional study. Int. J. Hyg. Environ. Health 2017, 220, 1074-1080. [CrossRef] [PubMed]

18. Szyszkowicz, M.; Kousha, T.; Kingsbury, M.; Colman, I. Air pllution and emergency department visits for depression: A multicity case-crossover study. Environ. Health Insights 2016, 10, EHI.S40493. [CrossRef] [PubMed]

19. Ingber, S.Z.; Pohl, H.R. Windows of sensitivity to toxic chemicals in the motor effects development. Regul. Toxicol. Pharmacol. 2016, 74, 93-104. [CrossRef] [PubMed]

20. Cabral Pinto, M.M.S.; Paula Marinho-Reis, A.; Almeida, A.; Ordens, C.M.; Freitas, S.; Simões, M.R.; Moreira, P.I.; Dinis, P.A.; LuísaDiniz, M.; Ferreira da Silva, E.A.; et al. Human predisposition to cognitive impairment and its relation with environmental exposure to potentially toxic elements. Environ. Geochem. Health 2018, 40, 1767-1784. [CrossRef] [PubMed]

21. Hardos, J.E.; Whitehead, L.W.; Han, I.; Ott, D.K.; Waller, D.K. Depression prevalence and exposure to organophosphate esters in aircraft maintenance workers. Aerosp. Med. Hum. Perform. 2016, 87, 712-717. [CrossRef]

22. Edwards, D.; Besseling, E. Relationship between depression, anxiety, sense of coherence, social support and religious involvement in a small rural community affected by industrial relations conflict. S. Afr. J. Psychol. 2001, 31, 62-71. [CrossRef]

23. Patel, V.; Abas, M.; Broadhead, J.; Todd, C.; Reeler, A. Depression in developing countries: Lessons from Zimbabwe. BMJ 2001, 322, 482-484. [CrossRef]

24. Patel, V.; Todd, C.; Winston, M.; Gwanzura, F.; Simunyu, E.; Acuda, W.; Mann, A. Common mental disorders in primary care in Harare, Zimbabwe: Associations and risk factors. Br. J. Psychiatry 1997, 171, 60-64. [CrossRef]

25. Tansella, M.; Thornicroft, G. On vulnerability to common mental disorders. In Common Mental Disorders in Primary Care; Tansella, M., Thornicroft, G., Eds.; Routledge: London, UK, 2003; pp. 61-78.

26. Albert, P.R. Why is depression more prevalent in women? J. Psychiatry Neurosci. 2015, 40, 219-221. [CrossRef]

27. Kuehner, C. Why is depression more common among women than among men? Lancet Psychiatry 2017, 4, 146-158. [CrossRef]

28. Pham, M.C.; Vuong, Q.H. Kinh tế Việt Nam: Thăng trầm và đột phá [Vietnam's economy: Vicissitude and breakthrough]; National Political-Truth Publisher: Hanoi, Vietnam, 2009.

29. Vuong, D.A.; Van Ginneken, E.; Morris, J.; Ha, S.T.; Busse, R. Mental health in Vietnam: Burden of disease and availability of services. Asian J. Psychiatry 2011, 4, 65-70. [CrossRef]

30. Kessler, R.C.; Angermeyer, M.; Anthony, J.C.; De Graaf, R.O.N.; Demyttenaere, K.; Gasquet, I. Lifetime prevalence and age-of-onset distributions of mental disorders in the World Health Organization's World Mental Health Survey Initiative. World Psychiatry 2007, 6, 168-176.

31. Fakhari, A.; Ranjbar, F.; Dadashzadeh, H.; Moghaddas, F. An epidemiological survey of mental disorders among adults in the North, West Area of Tabriz, Iran. Pak. J. Med. Sci. 2007, 23, 54-58.

32. Kroenke, K.; Spitzer, R.L.; Williams, J.B. The PHQ-9: Validity of a brief depression severity measure. J. Gen. Intern. Med. 2001, 16, 606-613. [CrossRef]

33. Mujahid, M.S.; Diez Roux, A.V.; Morenoff, J.D.; Raghunathan, T. Assessing the measurement properties of neighborhood scales: From psychometrics to ecometrics. Am. J. Epidemiol. 2007, 165, 858-867. [CrossRef]

34. Marco, M.; Gracia, E.; Tomás, J.M.; López-Quílez, A. Assessing neighborhood disorder: Validation of a three-factor observational scale. Eur. J. Psychol. Appl. Leg. Context 2015, 7, 81-89. [CrossRef]

35. McDonald, R.; Vechi, C.; Bowman, J.; Sanson-Fisher, R. Mental health status of a Latin American community in New South. Wales. Aust. N. Z. J. Psychiatry 1996, 30, 457-462. [CrossRef]

36. Zhong, B.L.; Liu, T.B.; Chan, S.S.M.; Jin, D.; Hu, C.Y.; Dai, J.; Chiu, H.F.K. Common mental health problems in rural-to-urban migrant workers in Shenzhen, China: Prevalence and risk factors. Epidemiol. Psychiatr. Sci. 2018, 27, 256-265. [CrossRef]

37. Loret de Mola, C.; Stanojevic, S.; Ruiz, P.; Gilman, R.H.; Smeeth, L.; Miranda, J.J. The effect of rural-to-urban migration on social capital and common mental disorders: PERU MIGRANT study. Soc. Psychiatry Psychiatr. Epidemiol. 2012, 47, 967-973. [CrossRef] 
38. Butler, M.; Warfa, N.; Khatib, Y.; Bhui, K. Migration and common mental disorder: An improvement in mental health over time? Int. Rev. Psychiatry 2015, 27, 51-63. [CrossRef] [PubMed]

39. Lau, J.T.; Cheng, Y.; Gu, J.; Zhou, R.; Yu, C.; Holroyd, E.; Yeung, N.C. Suicides in a mega-size factory in China: Poor mental health among young migrant workers in China. Occup. Environ. Med. 2012, 69, 526. [CrossRef] [PubMed]

40. Zhong, B.L.; Liu, T.B.; Chan, S.S.; Jin, D.; Hu, C.Y.; Dai, J.; Chiu, H.F. Prevalence and correlates of major depressive disorder among rural-to-urban migrant workers in Shenzhen, China. J. Affect Disord. 2015, 183, 1-9. [CrossRef]

41. Amagasa, T.; Nakayama, T. Relationship between long working hours and depression: A 3-year longitudinal study of clerical workers. J. Occup. Environ. Med. 2013, 55, 863-872. [CrossRef] [PubMed]

42. Yoon, Y.; Ryu, J.; Kim, H.; won Kang, C.; Jung-Choi, K. Working hours and depressive symptoms: The role of job stress factors. Ann. Occup. Environ. Med. 2018, 30, 46. [CrossRef]

43. Rodic, D.; Meyer, A.H.; Meinlschmidt, G. The Association between Depressive Symptoms and Physical Diseases in Switzerland: A Cross-Sectional General Population Study. Public Health 2015, 3, 47. [CrossRef] [PubMed]

44. Schmaus, B.J.; Laubmeier, K.K.; Boquiren, V.M.; Herzer, M.; Zakowski, S.G. Gender and stress: Differential psychophysiological reactivity to stress reexposure in the laboratory. Int. J. Psychophysiol. 2008, 69, 101-106. [CrossRef]

45. Park, J.; Han, M.; Park, J.; Ryu, S. Prevalence of Depressive Symptoms and Related Factors in Korean Employees: The Third Korean Working Conditions Survey (2011). Int. J. Environ. Res. Public Health 2016, 13, 424. [CrossRef]

46. Silveira, E.R.; Ebrahim, S. Social determinants of psychiatric morbidity and well-being in immigrant elders and whites in east London. Int. J. Geriatr. Psychiatry. 1998, 13, 801-812. [CrossRef]

47. Rosario, M.; Schrimshaw, E.W.; Hunter, J. Cigarette smoking as a coping strategy: Negative implications for subsequent psychological distress among lesbian, gay, and bisexual youths. J. Pediatr. Psychol. 2011, 36, 731-742. [CrossRef] [PubMed]

48. Kassel, J.D.; Evatt, D.P.; Greenstein, J.E.; Wardle, M.C.; Yates, M.C.; Veilleux, J.C. The acute effects of nicotine on positive and negative affect in adolescent smokers. J. Abnorm. Psychol. 2007, 116, 543-553. [CrossRef] [PubMed] 